\title{
Mentalizing impairment as a mediator between reported childhood abuse and outcome in nonaffective psychotic disorder
}

Citation for published version (APA):

Weijers, J., Fonagy, P., Eurelings-Bontekoe, E., Termorshuizen, F., Viechtbauer, W., \& Selten, J. P. (2018). Mentalizing impairment as a mediator between reported childhood abuse and outcome in nonaffective psychotic disorder. Psychiatry Research, 259, 463-469.

https://doi.org/10.1016/j.psychres.2017.11.010

Document status and date:

Published: 01/01/2018

DOI:

10.1016/j.psychres.2017.11.010

Document Version:

Publisher's PDF, also known as Version of record

Document license:

Taverne

Please check the document version of this publication:

- A submitted manuscript is the version of the article upon submission and before peer-review. There can be important differences between the submitted version and the official published version of record.

People interested in the research are advised to contact the author for the final version of the publication, or visit the DOI to the publisher's website.

- The final author version and the galley proof are versions of the publication after peer review.

- The final published version features the final layout of the paper including the volume, issue and page numbers.

Link to publication

\footnotetext{
General rights rights.

- You may freely distribute the URL identifying the publication in the public portal. please follow below link for the End User Agreement:

www.umlib.nl/taverne-license

Take down policy

If you believe that this document breaches copyright please contact us at:

repository@maastrichtuniversity.nl

providing details and we will investigate your claim.
}

Copyright and moral rights for the publications made accessible in the public portal are retained by the authors and/or other copyright owners and it is a condition of accessing publications that users recognise and abide by the legal requirements associated with these

- Users may download and print one copy of any publication from the public portal for the purpose of private study or research.

- You may not further distribute the material or use it for any profit-making activity or commercial gain

If the publication is distributed under the terms of Article $25 \mathrm{fa}$ of the Dutch Copyright Act, indicated by the "Taverne" license above, 


\title{
Mentalizing impairment as a mediator between reported childhood abuse and outcome in nonaffective psychotic disorder
}

\author{
J. Weijers ${ }^{\mathrm{a}, \mathrm{b}, *}$, P. Fonagy ${ }^{\mathrm{c}}$, E. Eurelings-Bontekoe ${ }^{\mathrm{d}}$, F. Termorshuizen ${ }^{\mathrm{a}}$, W. Viechtbauer $^{\mathrm{b}}$, \\ J.P. Selten ${ }^{\mathrm{a}, \mathrm{b}}$ \\ a Rivierduinen Institute for Mental Health Care, Sandifortdreef 19, 2333 ZZ Leiden, The Netherlands \\ ${ }^{\mathrm{b}}$ Department of Psychiatry and Neuropsychology, School for Mental Health and Neuroscience, Maastricht University, Universiteitssingel 50, 6229 ER Maastricht, The \\ Netherlands \\ ${ }^{\mathrm{c}}$ Research Department of Clinical, Educational, and Health Psychology, University College London, Gower Street, London WC1E 6BT, United Kingdom \\ d Department of Clinical Psychology, Health, and Neuropsychology, Leiden University, Wassenaarseweg 52, 2333 AK Leiden, The Netherlands
}

\section{A R T I C L E I N F O}

\section{Keywords:}

Mentalization

Psychosis

Positive symptoms

Negative symptoms

Social functioning

\begin{abstract}
A B S T R A C T
Reported childhood abuse has been linked to the severity of clinical symptoms and social dysfunction in non-affective psychotic disorder. Impaired mentalizing ability may be one of the mechanisms accounting for this effect. This study examined whether impaired mentalizing mediates the effect of reported childhood abuse on positive symptoms, negative symptoms, and social dysfunction. Eighty-seven patients with non-affective psychotic disorder were examined. Reported childhood abuse was measured using the Childhood Experience of Care and Abuse interview. Additionally, the Social Functioning Scale and the Positive and Negative Syndrome Scale were used. The Hinting Task was used to measure mentalizing impairment. Reported childhood abuse was significantly related to the severity of positive and negative symptoms, not to social dysfunction. Reported childhood abuse was also related to mentalizing impairment. Mentalizing impairment was related to negative symptoms, but not to positive symptoms or social dysfunction. Mentalizing impairment accounted for $40 \%$ of the association between reported childhood abuse and negative symptoms, indicating partial mediation. A sensitivity analysis revealed that the mediating effect was only observed in those who reported fairly severe childhood abuse.
\end{abstract}

\section{Introduction}

Patients with non-affective psychotic disorder are almost three times as likely as non-psychiatric controls to report a history of abuse in childhood (Varese et al., 2012). Moreover, reported childhood abuse is associated with the severity of positive and negative symptoms (Longden et al., 2015; Schenkel et al., 2005; Spauwen et al., 2006; van Dam et al., 2015), and there is some evidence for an association with social dysfunction as well (Alameda et al., 2015; Stain et al., 2013). However, little is known about the underlying mechanisms. Recently, it has been proposed that one such mechanism is an impaired ability to mentalize (van Os et al., 2010). Mentalizing has been defined as the capacity to understand one's own and others' behavior in terms of mental states, such as intentions, wishes, beliefs, and emotions (Bateman and Fonagy, 2012). Patients with non-affective psychotic disorder have been shown to perform poorly on different dimensions of mentalizing, such as 'theory of mind' (i.e. the ability to infer mental states from other's behavior; Sprong et al., 2007), identifying and describing their own emotional states (O'Driscoll et al., 2014) and recognizing others' emotional states (Trémeau, 2006).

No study to date has examined the possible mediating role of impaired mentalizing in the relation between reported childhood abuse and the outcome of non-affective psychotic disorder, even though it is a plausible underlying mechanism. Abuse in childhood has been related to impaired or delayed development of mentalizing (Cicchetti et al., 2003; Pears and Fisher, 2005; Ensink et al., 2015) and poor understanding or discrimination of emotions (Rogosch et al., 1995; Camras et al., 1996; Shipman and Zeman, 1999; Pollak et al., 2000; Edwards et al., 2005).

Parental abuse is considered to be particularly detrimental to the development of mentalizing, because the groundwork of mentalizing is laid through day-to-day interactions with primary caregivers (Fonagy et al., 2004). By labelling the child's mental states, caregivers help the child understand his/her own mental states (Kim, 2015), which may be viewed as a prerequisite for the ability to infer the mental states of others (Brüne, 2005). In contrast, parental abuse can be viewed as

\footnotetext{
Abbreviations: CECA, Childhood Experience of Care and Abuse; HT, Hinting Task; SFS, Social Functioning Scale; PANSS, Positive and Negative Syndrome Scale

* Correspondence to: GGZ Rivierduinen, room C3.08,Sandifortdreef 19, 2333 ZZ Leiden, The Netherlands.

E-mail address: j.weijers@rivierduinen.nl (J. Weijers).
} 
reflecting an inability on the part of the caregiver to mentalize the inner experiences of the child, thereby depriving the child of a good role model for mentalizing (Kim, 2015). Additionally, parental abuse has been argued to impede mentalizing by inducing a lessened motivation to mentalize in the child, or even phobic avoidance of mentalizing, because reflecting on a caregiver's malevolent or uncaring mental states is overwhelmingly painful (Chiesa and Fonagy, 2014).

Another line of research suggests that an impaired ability to represent mental states may contribute to the severity of positive and negative symptoms in non-affective psychotic disorder (Frith, 2014). For instance, an inability to identify one's own intentions may contribute to the experience that one's actions are caused or influenced by an outside force (i.e., delusions of control). Moreover, verbal hallucinations and the experience of thought insertion could arguably be viewed as the incorrect representation of one's own thoughts. Delusions of persecution and reference, by definition, involve the misrepresentation of another person's intentions. Concerning negative symptoms, the inability to represent what others think, intend, or desire is likely to complicate social interactions, in turn increasing the tendency to withdraw from such situations. Similarly, the inability to use gestures, facial expressions, and tone of voice to express emotions commonly referred to as 'flattened affect' - may be exacerbated by an inability to understand the particular mental states conveyed by such communicational cues. Lastly, failing to identify one's own goals may contribute to avolition.

Partial support for this theory comes from a number of studies that have consistently associated impaired mentalizing ability with negative symptoms (Doody et al., 1998; Greig et al., 2004; Sergi et al., 2007) and social dysfunction (Couture et al., 2006; Fett and Maat, 2011). However, support for an association between impaired mentalizing ability and positive symptoms is weaker. Some studies have found such an association (Corcoran et al., 1995; Frith and Corcoran, 1996), but a majority of reviewed studies failed to do so (Garety and Freeman, 1999).

We do not presume that impaired mentalizing is the sole mechanism whereby childhood abuse can affect psychopathology of adult patients. A few mechanisms have already been suggested, including dopamine sensitization (Selten et al., 2013), insecure attachment (Read and Gumley, 2010), poorer emotional regulation (Lincoln et al., 2017), higher emotional reactivity to stress (Lardinois et al., 2011), and cognitive impairment (Grant and Beck, 2009). However, such pathways may interact with impaired mentalizing. For example, an insecure attachment style has been related to mentalizing impairment in a sample of patients with psychotic disorder (MacBeth et al., 2011). Attachmentrelated stress has also been implicated in poorer performance on mentalizing tasks (Nolte et al., 2013).

In the current study, we explored [1] whether reported childhood abuse is related to the severity of positive and negative symptoms and the level of social dysfunction; [2] whether reported childhood abuse is related to mentalizing impairment; [3] whether mentalizing impairment is related to the severity of positive symptoms, negative symptoms, and level of social dysfunction; and [4] whether impaired mentalizing explains at least part of the association between reported childhood abuse and these outcome variables.

\section{Methods}

\subsection{Participants and procedure}

Ninety outpatients with non-affective psychotic disorder were recruited from community treatment teams at regional mental health care institutes in the Netherlands (the Rivierduinen Institute for Mental Health Care located in Leiden, Voorhout, and Zoetermeer, and the Altrecht Institute for Mental Health Care in Zeist). The intervention teams were asked to refer any patients eligible for the study. Those referred to the study were contacted to assess their interest in participating and were screened regarding in- and exclusion criteria. Patients had to be at least 18 years old, have a non-affective psychotic disorder diagnosis from a psychiatrist, and be in treatment for a period between 6 months and 10 years to be eligible for inclusion. The diagnosis of nonaffective psychotic disorder was also confirmed by researchers using the Comprehensive Assessment of History and Symptoms interview (Andreasen et al., 1992). Participants with intellectual disabilities, illiteracy, or lack of mastery of the Dutch language were excluded from participation. All participants provided written informed consent after the procedures had been fully explained and before testing. The tests were administered by trained researchers with at least a bachelor degree in (applied) psychology. The current study is part of a larger research project for which ethical approval was given by the Medical Research Ethics Committee of the University Hospital Maastricht and Maastricht University (13-3-066.5/ab).

\subsection{Measures}

The Childhood Experience of Care and Abuse (CECA; Bifulco et al., 1994), a semi-structured interview, was used to assess childhood abuse (at age 0-16 years). Childhood abuse comprised four types of maltreatment: psychological abuse, physical abuse, sexual abuse, and parental conflict. Based on theory, the link with impaired mentalizing is likely to be strongest for parental abuse (Chiesa and Fonagy, 2014; Kim, 2015). Therefore, only abuse perpetrated by caregivers was taken into account. Psychological abuse comprised extreme criticism, rejection, humiliation, or terrorizing by a caregiver. Physical abuse was defined as bodily harm inflicted by a caregiver that resulted in at least bruising. Sexual abuse was defined as the participant's report of any unwanted sexual incident perpetrated by a caregiver. Parental conflict was defined as the amount of fighting between the caregivers and/or with the child. Each type of abuse was scored for both frequency and intensity. Intensity of abuse was rated on a four-point Likert scale: 0 (none), 1 (some), 2 (moderate), 3 (marked), with the exception of parental conflict, which was scored on a five-point scale that also included 4 (violence). Frequency of abuse was rated on a five-point Likert-scale: 0 (never), 1 (rarely: once or twice), 2 (incidentally: more than two times, but not monthly), 3 (regularly: monthly or more often), 4 (often: weekly or more often). The severity score for each type of abuse was the product of intensity and frequency. The total reported childhood abuse score, ranging from 0 to 52 , was the sum of the severity scores for each subtype of abuse.

The ability to mentalize was operationalized as the capacity to attribute intentions to others. This was measured using the Hinting Task (HT; Corcoran et al., 1995), in which participants read extracts that describe an interaction between two characters. In each case, one of the characters says something with an implicit message. To infer the implicit message from the literal one, an understanding of the character's beliefs or feelings is needed. If the participant infers the message correctly, 2 points are scored. If a hint is needed in order to infer the message correctly, a score of 1 is given. If the answer is incorrect or the participant does not know, 0 points are scored. There are 10 passages, so participants can score up to 20 points. For ease of interpretation the HT was reverse coded, so that higher scores reflected greater mentalizing impairment.

The Positive and Negative Syndrome Scale (PANSS) (Kay et al., 1987), an observer-rated instrument, was used to assess the severity of positive and negative symptoms during the 2 weeks preceding measurement. The positive syndrome scale comprises delusions, conceptual disorganization, hallucinations, excitement, grandiosity, suspiciousness, and hostility, rated on a seven-point Likert scale. The negative symptoms are represented by flattened affect, emotional withdrawal, poor rapport, passive social withdrawal, difficulty in abstract thinking, lack of spontaneity, and stereotyped thinking. Both scales have a range of 7-49. Interrater reliability was assessed by means of a videotaped interview, rated independently by all raters. Inter-rater reliability was high for the average of PANSS items (ICC $=0.91$ ). 
Social dysfunction was measured using the Social Functioning Scale (SFS), a self-report questionnaire (Birchwood et al., 1990). The SFS contains seven dimensions (social withdrawal, interpersonal communication, independence (competence), independence (performance), recreational activities, social activities, and employment) and has been found to be reliable, valid, sensitive, and responsive to change (Birchwood et al., 1990). The overall social functioning score is determined by averaging all subdomains, resulting in a potential range from 59.7 to 134.9. Again, for ease of interpretation the scale was reverse coded, so that higher a score on the SFS indicated greater dysfunction.

\subsection{Statistical analyses}

Three mediator models were tested, one for each outcome variable (positive symptoms, negative symptoms, and social dysfunction), with reported childhood abuse as the independent variable and mentalizing impairment as the mediator in each model. SPSS version 22 combined with Hayes's PROCESS macro (Hayes and Preacher, 2013) was used for the mediation analyses. The process macro uses non-parametric bootstrapping, which involves random resampling of observations with replacement to obtain confidence intervals for the indirect effect (and functions thereof). The bootstrap confidence intervals were based on 10,000 resamples. Effects are considered significant if the confidence interval does not contain 0 . Mediation is present if the indirect effect ( $a$ and $b$ ) of the independent variable (reported childhood abuse) through the mediator (mentalizing impairment) on the outcome variables (positive symptoms, negative symptoms, and social dysfunction) is significant (i.e., the confidence interval does not contain 0 ) and the direct effect of the dependent variable on the outcome variable while accounting for the mediator $\left(c^{\prime}\right)$ is smaller than the total effect (c) (Fig. 1).

\section{Results}

\subsection{Sample characteristics}

Two participants dropped out of the study before completing all questionnaires, and another participant refused to answer questions regarding childhood experiences. They were excluded from analysis. The following results were obtained from analyses with the remaining 87 patients. Of these participants, $36.8 \%(n=32)$ reported no abuse, $63.2 \%(n=55)$ reported at least mild forms of abuse in one or more categories, and $37.9 \%(n=33)$ reported at least marked forms of abuse in one or more categories. Other descriptive statistics are presented in Table 1.
Table 1

Sociodemographic characteristics of sample $(\mathrm{N}=87)$.

\begin{tabular}{lll}
\hline Variable & Mean $\pm S D$ & Range \\
\hline Age (y) & $31.7 \pm 8.2$ & $19-57$ \\
Years since onset first psychosis & $5.7 \pm 4.0$ & $1-22$ \\
Reported Childhood Abuse & $8.7 \pm 10.3$ & $0-43$ \\
$\quad$ Parental conflict & $5.5 \pm 5.8$ & $0-16$ \\
Physical abuse & $1.2 \pm 2.7$ & $0-12$ \\
Psychological abuse & $1.8 \pm 3.9$ & $0-12$ \\
Sexual abuse & $0.1 \pm 0.7$ & $0-6$ \\
& & \\
Variable & $n$ & Percentage \\
\hline Sex & & \\
Male & 56 & 64.4 \\
DSM-IV diagnosis & & 63.2 \\
Schizophrenia & 55 & 16.1 \\
Psychotic disorder Nos & 14 & 13.8 \\
Schizoaffective disorder & 12 & 4.6 \\
Brief psychotic disorder & 4 & 2.3 \\
Delusional disorder & 2 & \\
\hline
\end{tabular}

\subsection{Main effects}

Reported childhood abuse was significantly related to the severity of positive symptoms $(b=0.11,95 \%$ confidence interval [0.02, 0.20$], p$ $=0.014)$ and negative symptoms $(b=0.17,95 \%$ confidence interval [0.06, 0.28], $p=0.004)$, but not to social dysfunction $(b=0.05,95 \%$ confidence interval $[-0.10,0.20], p=0.517)$. Furthermore, reported childhood abuse was related to mentalizing impairment $(b=0.06,95 \%$ confidence interval [0.01, 0.11], $p=0.027$ ). Mentalizing impairment was not associated with the severity of positive symptoms $(b=0.15$, $95 \%$ confidence interval $[-0.20,0.50], p=0.395)$, but it was associated with severity of negative symptoms $(b=1.20,95 \%$ confidence interval [0.82, 1.58], $p<0.001$ ), and there was a positive, but not a significant association between mentalizing impairment and social dysfunction $(b=0.55,95 \%$ confidence interval $[-0.05,1.14], p=$ 0.073). Interpretation of these results did not change when we added the other outcome variables as covariates to each separate analysis.

\subsection{Mediation}

In the case of negative symptoms only, the prerequisites of mediation - a significant association between independent variable, dependent variable, and mediator - were met. There was a significant indirect

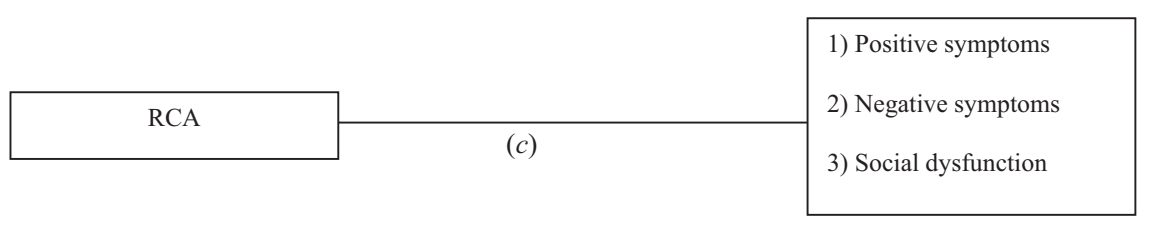

Fig. 1. Mediational model with reported childhood abuse (RCA) as independent variable, mentalizing impairment as mediator, and positive symptoms, negative symptoms, and social dysfunction as dependent variables.

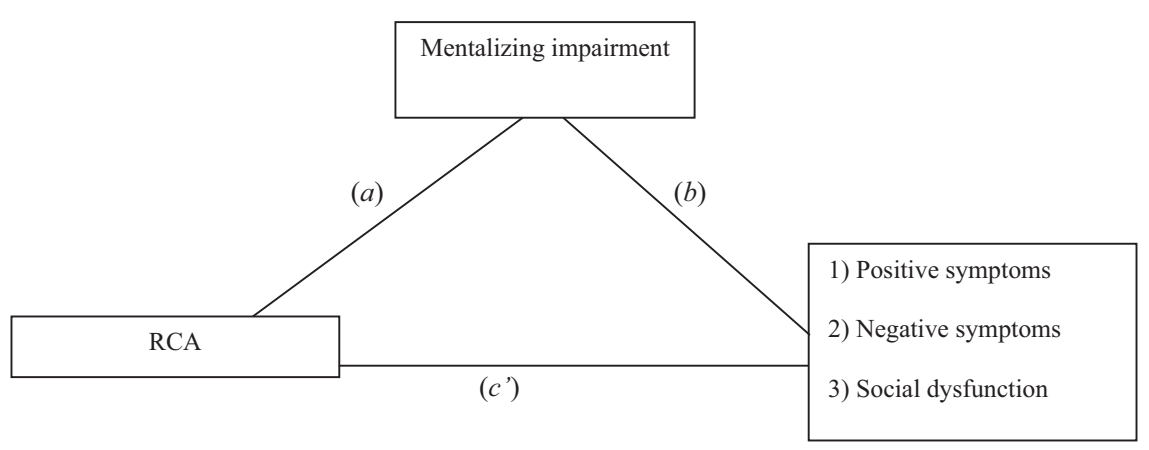


effect of reported childhood abuse on negative symptoms through mentalizing impairment, path a through $\mathrm{b}$ in Fig. $1(b=0.07,95 \%$ confidence interval [0.002, 0.17], $p=0.039$ ), indicative of a mediation effect. The total effect of childhood abuse on negative symptoms path $\mathrm{c}$ in Fig. $1(b=0.17,95 \%$ confidence interval $[0.06,0.28], p=0.004)$ was reduced by about $40 \%$ when mentalizing impairment was accounted for, path $c^{\prime}$ in Fig. 1 ( $b=0.10,95 \%$ confidence interval [0.003, $0.20], p=0.043$ ), indicating partial mediation.

\subsection{Sensitivity analysis}

The above analysis assumes that all variables are related in a linear fashion, however curve estimations revealed that a quadratic term may be a better fit for the relation between reported childhood abuse and negative symptom severity $\left(R^{2}=0.180, p<0.001\right)$, than a linear one $\left(R^{2}=0.095, p=0.004\right)$. A quadratic term also better fitted the relation between reported childhood abuse and impaired mentalizing $\left(R^{2}=\right.$ $0.082, p=0.027)$, instead of a linear one $\left(R^{2}=0.056, p=0.027\right)$. Both negative symptoms and mentalizing impairment increase exponentially as reported childhood abuse increases.

The use of a traditional mediation analysis in this case may be problematic, because it calculates the significance of one single indirect effect, assuming that the relationship between the independent variable, mediator and dependent variable is linear. However, in the current case the indirect effect is unlikely to be identical for each level of reported childhood abuse. We therefore also calculated the indirect effect using a mediation analysis that accounts for quadratic relationships, using the MEDCURVE macro (Hayes and Preacher, 2010). "Instantaneous indirect effects" were generated at different levels of reported childhood abuse (one standard deviation above and below the sample mean) as suggested by Hayes and Preacher (2010). Results showed, that only in the subgroup reporting relatively high childhood abuse (CECA $\geq 19$ ), there was a significant indirect effect of childhood abuse $(\theta=0.09,95 \%$ confidence interval $[0.01,0.22])$. This model predicted about $40 \%\left(R^{2}=0.394, p<0.001\right)$ of the variance in negative symptom severity.

\section{Discussion}

\subsection{Discussion of the results}

This study tested the hypothesis that mentalizing impairment constitutes a pathway through which parental abuse affects clinical and functional outcomes in non-affective psychotic disorder. The majority of non-affective psychotic disorder patients in our sample reported experiencing parental abuse during their childhood. The severity of this abuse was associated with the levels of positive and negative symptoms and with mentalizing impairment, but not with social dysfunction. Mentalizing impairment, in turn, showed a significant relationship to the severity of negative symptoms, but no such relationship to positive symptoms or social dysfunction. Lastly, the relationship between reported childhood abuse and negative symptoms was partly mediated by mentalizing impairment, accounting for approximately $40 \%$ of the effect. A sensitivity analysis, which treated the relations between reported childhood abuse, negative symptoms and mentalizing impairment as quadratic, revealed that the mediating role of mentalizing impairment was only significant in the case of fairly severe abuse.

\subsection{Comparison to previous findings}

The current results replicate previous findings regarding the relationship of reported childhood abuse to clinical outcome (Schenkel et al., 2005; Spauwen et al., 2006; Longden et al., 2015; van Dam et al., 2015) and support the theory that parental abuse is related to mentalizing impairment (Chiesa and Fonagy, 2014; Kim, 2015). While the findings do not support the idea that impaired mentalizing is related to positive symptoms, they do provide evidence of such a relationship to negative symptoms, in line with many previous studies (Garety and Freeman, 1999; Doody et al., 1998; Mitchley et al., 1998; Greig et al., 2004; Sergi et al., 2007). Positive symptoms may not reflect an overall impaired ability to represent mental states, but rather a tendency to excessively do so, or to 'hypermentalize' (Abu-Akel and Bailey, 2000; Clemmensen et al., 2016). Such a tendency has also been suggested to be state-like in nature, occurring only in specific circumstances (Walston et al., 2000; Charlton, 2003), which would explain the normal mentalizing performances of patients with predominantly positive symptoms in most studies (Garety and Freeman, 1999). Interestingly, the current results also seem to echo recent observations that loneliness mediates the relation between social adversity and negative, but not positive symptoms (Jaya et al., 2016). This may not come as a surprise as loneliness has been related to attachment-related stress (e.g. Wei et al., 2005), which in turn has been linked to impaired mentalizing (Nolte et al., 2013). Whatever the case may be, the current results support the notion that adversity may be related to negative and positive symptoms through different pathways, as Bentall and colleagues have recently suggested (2014). Unexpectedly, we did not replicate the previously established relationship between reported childhood abuse and social functioning (Lysaker et al., 2004; Stain et al., 2013; Alameda et al., 2015). A possible explanation for this discrepancy may be the amount of time since onset of psychosis. Previous studies observed such associations either before (Spauwen et al., 2006; Tikka et al., 2013), or shortly after (Stain et al., 2013; Alameda et al., 2015) onset of psychosis. The current sample consisted of patients who, on average, experienced their first psychotic episode more than 5 years ago. Social functioning deteriorates most in the first 5 years after onset of psychosis; the rate of this deterioration is influenced by factors such as drug abuse, lack of social support, and symptom distress (Birchwood et al., 1998). Possibly, social functioning is affected by a history of childhood abuse up to and around the onset of psychosis, but that other factors account for its decline afterwards. Alternatively, the effect of childhood abuse on social functioning may occur only in certain subgroups. For example, Boyette et al. (2014) found that the impact of reported childhood abuse on social dysfunction partly depends on the personality of the patient, whereas Lysaker et al. (2004) found that survivors of sexual abuse specifically showed poorer vocational outcome.

Furthermore, the positive relationship between mentalizing impairment and social dysfunction, although in the expected direction, was not significant. The relation between mentalizing and functional outcome likely depends on the specific subdomains examined, as Couture et al. (2006) have suggested.

\subsection{Clinical implications}

This study provides initial support for the theory that impaired mentalizing ability is a potential pathway through which parental abuse affects the severity of negative symptoms in non-affective psychotic disorder. Although more research is needed to come to causal conclusions about the potentially pathogenic role of impaired mentalizing, it may be fruitful to examine the usefulness of targeting mentalizing ability as a treatment strategy for non-affective psychotic disorder. For example, mentalization based treatment (Brent et al., 2014; Weijers et al., 2016) and metacognitive therapy (Van Donkersgoed et al., 2014) both target mentalizing by helping the patient to become aware and elaborate on their own affective states as well as those of others. Alternatively, mentalization based treatment could potentially be implemented as a preventive therapy focusing on those at risk for psychosis (Debbané et al., 2016). Furthermore, the results underscore the importance of taking into account the possibility of patients having experienced abuse in childhood and their level of mentalizing impairment, as these factors negatively contribute to outcome in different ways (Selten and Cantor-Graae, 2014). 


\subsection{Limitations and conclusions}

Naturally, some limitations apply. First, childhood abuse scores were based on patient accounts. Some may argue this to be problematic since the validity of retrospective reports, especially by psychiatric patients has been questioned (Susser and Widom, 2012). However, reports of abuse by psychiatric patients, including those with psychosis, have generally been found to be reliable; (see Read et al., 2005 for an overview). Further, a prospective study of young people very likely to have been exposed to sexual abuse clearly showed an increased risk of schizophrenia (Cutajar et al., 2010).

Second, different forms of childhood abuse were pooled into a single severity score, because the relatively small sample size precluded sufficiently powered sub-group analyses. Future studies, involving larger sample sizes, should consider the effects of each subtype of abuse separately, as different types of abuse may contribute to different dimensions of symptomatology (Bentall et al., 2014).

Third, it is important to stress that evidence of mediation does not establish causality (Maxwell et al., 2011). A prospective study would therefore be preferable in order to make more robust claims concerning causality.

Fourth, only one type of mentalizing deficit was accounted for in this study. The ability to infer mental states of others, as measured by the hinting task, is a cognitive, other-oriented form of mentalizing and is only a partial indicator of the total construct of mentalizing. A number of dimensional axes have been proposed to underlie mentalizing, including cognitive-affective, implicit-explicit, and self-other oriented axes (Fonagy and Luyten, 2012). Specific mentalizing deficits may affect specific clinical symptoms differently, as has recently been argued (Debbané et al., 2016). Indeed, the severity of positive symptoms seems especially susceptible to deficits in self-oriented mentalizing (i.e. the ability to be aware of and identify self-generated mental events; e.g. Brunelin et al., 2007). Future studies should take different forms of mentalizing into account.

This study integrated two lines of research: one that highlights the role of impaired mentalizing regarding clinical and functional outcome in non-affective psychotic disorder (Frith, 2014) and another that underscores the developmental nature of mentalizing ability (Fonagy et al., 2004). Although recent research has increasingly focused on the role of mentalizing in non-affective psychotic disorder, so far it has largely ignored the developmental origins of mentalizing ability. The current findings offer initial evidence that impaired mentalizing may constitute a pathway whereby childhood abuse affects adult negative symptoms, although such an effect is only likely to be observed when childhood abuse is fairly severe. Based on these findings, we believe that an understanding of the origins of impaired mentalizing may offer more insight into the pathogenesis of non-affective psychotic disorder.

\section{Acknowledgements}

None

\section{Funding}

This research did not receive any specific grant from funding agencies in the public, commercial, or not-for-profit sectors. Peter Fonagy was in part supported by the National Institute for Health Research (NIHR) (NF-SI-0514-10157) Collaboration for Leadership in Applied Health Research and Care (CLAHRC) North Thames at Barts Health NHS Trust and is in receipt of NIHR Senior Investigator Award (Ref. NF-SI-0514-10157). The views expressed are those of the author (s) and not necessarily those of the NHS, the NIHR or the Department of Health.

\section{Contributors}

Author JW designed the study and wrote the first draft. PF edited the manuscript. All authors reviewed, commented on and have approved the final manuscript.

\section{Disclosure of interest}

The authors declare that they have no competing interest.

\section{Appendix A}

For potential meta-analytic purposes, the original (not the reverse coded) means, standard deviations and correlations are presented in Table A1.

Table A1

Means, standard deviations, and correlations of the independent, dependent, and mediator variables $(\mathrm{N}=87)$.

\begin{tabular}{|c|c|c|c|c|c|c|}
\hline \multirow[b]{2}{*}{ Variable } & \multicolumn{6}{|c|}{ Pearson correlation } \\
\hline & $\begin{array}{l}\text { Mean } \pm \text { SD } \\
(\min -\max )\end{array}$ & CECA & $\begin{array}{l}\text { PANSS } \\
\text { (pos) }\end{array}$ & $\begin{array}{l}\text { PANSS } \\
\text { (neg) }\end{array}$ & SFS & HT \\
\hline CECA & $\begin{array}{l}8.6 \pm 10.3 \\
(0-43)\end{array}$ & 1 & $0.26^{*}$ & $0.31^{* * *}$ & -0.09 & $-0.24^{*}$ \\
\hline $\begin{array}{l}\text { PANSS } \\
\quad \text { Positive }\end{array}$ & $\begin{array}{l}11.6 \pm 4.4 \\
(7-27)\end{array}$ & & 1 & $0.22^{*}$ & -0.09 & -0.10 \\
\hline $\begin{array}{l}\text { PANSS } \\
\quad \text { Negative }\end{array}$ & $\begin{array}{l}12.0 \pm 5.5 \\
(7-31)\end{array}$ & & & 1 & -0.16 & $-0.56^{* * *}$ \\
\hline SFS & $\begin{array}{l}109.1 \pm 7.7 \\
(87.1-129.1)\end{array}$ & & & & 1 & 0.20 \\
\hline HT & $\begin{array}{l}17.0 \pm 2.6 \\
(9-20)\end{array}$ & & & & & 1 \\
\hline
\end{tabular}

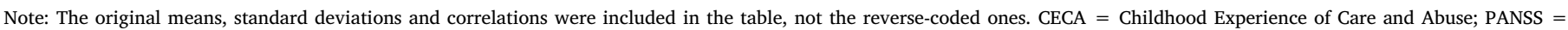
Positive and Negative Symptoms Scale; SFS = Social Functioning Scale; HT = Hinting Task.

* Correlation is Significant at the 0.05 level.

** Correlation is significant at the 0.01 level. 


\section{References}

Abu-Akel, A., Bailey, A.L., 2000. Letter. Psychol. Med. 30 (3), 735-738.

Alameda, L., Ferrari, C., Baumann, P., Gholam-Rezaee, M., Do, K., Conus, P., 2015. Childhood sexual and physical abuse: age at exposure modulates impact on func tional outcome in early psychosis patients. Psychol. Med. 45 (13), 2727-2736.

Andreasen, N.C., Flaum, M., Arndt, S., 1992. The Comprehensive Assessment of Symptoms and History (CASH): an instrument for assessing diagnosis and psychopathology. Arch. General. Psychiatry 49 (8), 615-623.

Bateman, A.W., Fonagy, P., 2012. Handbook of Mentalizing in Mental Health Practice. American Psychiatric Publishing, Inc., Arlington.

Bentall, R.P., de Sousa, P., Varese, F., Wickham, S., Sitko, K., Haarmans, M., Read, J., 2014. From adversity to psychosis: pathways and mechanisms from specific adversities to specific symptoms. Soc. Psychiatry Psychiatr. Epidemiol. 49 (7), 1011-1022.

Bifulco, A., Brown, G.W., Harris, T.O., 1994. Childhood Experience of Care and Abuse (CECA): a retrospective interview measure. J. Child Psychol. Psychiatry 35 (8), 1419-1435.

Birchwood, M., Smith, J., Cochrane, R., Wetton, S., Copestake, S., 1990. The Social Functioning Scale. The development and validation of a new scale of social adjustment for use in family intervention programmes with schizophrenic patients. Br. J. Psychiatry 157 (6), 853-859.

Birchwood, M., Todd, P., Jackson, C., 1998. Early intervention in psychosis: the criticalperiod hypothesis. Int. Clin. Psychopharmacol. 13, 31-40.

Boyette, L.-L., van Dam, D., Meijer, C., Velthorst, E., Cahn, W., de Haan, L., Kahn, R., van Os, J., Wiersma, D., Bruggeman, R., 2014. Personality compensates for impaired quality of life and social functioning in patients with psychotic disorders who experienced traumatic events. Schizophr. Bull. 40 (6), 1356-1365.

Brent, B.K., Holt, D.J., Keshavan, M.S., Seidman, L.J., Fonagy, P., 2014. Mentalizationbased treatment for psychosis: linking an attachment-based model to the psychotherapy for impaired mental state understanding in people with psychotic disorders. Israer J. Psychiatry Relat. Sci. 51 (1), 17-24.

Brüne, M., 2005. "Theory of mind" in schizophrenia: a review of the literature. Schizophr. Bull. 31 (1), 21-42.

Brunelin, J., d'Amato, T., Brun, P., Bediou, B., Kallel, L., Senn, M., Poulet, E., Saoud, M., 2007. Impaired verbal source monitoring in schizophrenia: an intermediate trait vulnerability marker? Schizophr. Res. 89 (1), 287-292.

Camras, L.A., Sachs-Alter, E., Ribordy, S.C., 1996. Emotion understanding in maltreated children: recognition of facial expressions and integration with other emotion cues. In: Lewis, M., Sullivan, M.W. (Eds.), Emotional Development in Atypical Children. Lawrence Erlbaum Associates, Hillsdale, NJ, pp. 203-225.

Charlton, B.G., 2003. Theory of Mind Delusions and Bizarre Delusions in an Evolutionary Perspective: Psychiatry and the Social Brain. The Social Brain-Evolution and Pathology. John Wiley \& Sons, New York.

Chiesa, M., Fonagy, P., 2014. Reflective function as a mediator between childhood adversity, personality disorder and symptom distress. Personal. Ment. Health 8 (1), $52-66$.

Cicchetti, D., Rogosch, F.A., Maughan, A., Toth, S.L., Bruce, J., 2003. False belief understanding in maltreated children. Dev. Psychopathol. 15 (4), 1067-1091.

Clemmensen, L., van Os, J., Drukker, M., Munkholm, A., Rimvall, M., Væver, M., Rask, C.U., Bartels-Velthuis, A., Skovgaard, A., Jeppesen, P., 2016. Psychotic experiences and hyper-theory-of-mind in preadolescence-a birth cohort study. Psychol. Med. 46 (1), 87-101.

Corcoran, R., Mercer, G., Frith, C.D., 1995. Schizophrenia, symptomatology and social inference: investigating "theory of mind" in people with schizophrenia. Schizophr. Res. 17 (1), 5-13.

Couture, S.M., Penn, D.L., Roberts, D.L., 2006. The functional significance of social cognition in schizophrenia: a review. Schizophr. Bull. 32 (1), 44-63.

Cutajar, M.C., Mullen, P.E., Ogloff, J.R., Thomas, S.D., Wells, D.L., Spataro, J., 2010 Psychopathology in a large cohort of sexually abused children followed up to 43 years. Child Abus. Negl. 34 (11), 813-822.

Debbané, M., Salaminios, G., Luyten, P., Badoud, D., Armando, M., Tozzi, A.S., Fonagy, P., Brent, B.K., 2016. Attachment, neurobiology, and mentalizing along the psychosis continuum. Front. Hum. Neuroscience 10 (406), 1-22.

Doody, G., Götz, M., Johnstone, E., Frith, C., Owens, D.C., 1998. Theory of mind and psychoses. Psychol. Med. 28 (2), 397-405.

Edwards, A., Shipman, K., Brown, A., 2005. The socialization of emotional understanding: a comparison of neglectful and nonneglectful mothers and their children. Child Maltreat. 10 (3), 293-304.

Ensink, K., Normandin, L., Target, M., Fonagy, P., Sabourin, S., Berthelot, N., 2015. Mentalization in children and mothers in the context of trauma: an initial study of the validity of the Child Reflective Functioning Scale. Br. J. Dev. Psychol. 33 (2), 203-217.

Fett, A.-K.J., Maat, A., Group Investigators, 2011. Social cognitive impairments and psychotic symptoms: what is the nature of their association? Schizophr. Bull. 35, 573-588.

Fonagy, P., Gergely, G., Jurist, E.L., 2004. Affect Regulation, Mentalization and the Development of the Self. Karnac books, London.

Fonagy, P., Luyten, P., 2012. The multidimensional construct of mentalization and its relevance to understanding borderline personality disorder. In: From the Couch to the Lab: Trends in Psychodynamic Neuroscience. Oxford University Press, Oxford, p. 405.

Frith, C.D., 2014. The Cognitive Neuropsychology of Schizophrenia. Psychology Press, Hove.

Frith, C.D., Corcoran, R., 1996. Exploring 'theory of mind'in people with schizophrenia. Psychol. Med. 26 (3), 521-530.

Garety, P.A., Freeman, D., 1999. Cognitive approaches to delusions: a critical review of theories and evidence. Br. J. Clin. Psychol. 38 (2), 113-154.

Grant, P.M., Beck, A.T., 2009. Defeatist beliefs as a mediator of cognitive impairment, negative symptoms, and functioning in schizophrenia. Schizophr. Bull. 35 (4), 798-806.

Greig, T.C., Bryson, G.J., Bell, M.D., 2004. Theory of mind performance in schizophrenia: diagnostic, symptom, and neuropsychological correlates. J. Nerv. Ment. Dis. 192 (1), $12-18$.

Hayes, A.F., Preacher, K.J., 2010. Quantifying and testing indirect effects in simple mediation models when the constituent paths are nonlinear. Multivar. Behav. Res. 45 (4), 627-660.

Hayes, A.F., Preacher, K.J., 2013. Conditional process modeling: Using structural equation modeling to examine contingent causal processes. In: Structural Equation Modeling: A Second Course, vol. 2, pp. 217-264.

Jaya, E.S., Ascone, L., Lincoln, T.M., 2016. Social adversity and psychosis: the mediating role of cognitive vulnerability. Schizophr. Bull. 43 (3), 557-565.

Kay, S.R., Fiszbein, A., Opfer, L.A., 1987. The positive and negative syndrome scale (PANSS) for schizophrenia. Schizophr. Bull. 13 (2), 261-276.

Kim, S., 2015. The mind in the making: developmental and neurobiological origins of mentalizing. Personal. Disord.: Theory Res. Treat. 6 (4), 356-365.

Lardinois, M., Lataster, T., Mengelers, R., Van Os, J., Myin-Germeys, I., 2011. Childhood trauma and increased stress sensitivity in psychosis. Acta Psychiatr. Scand. 123 (1), 28-35.

Lincoln, T.M., Marin, N., Jaya, E.S., 2017. Childhood trauma and psychotic experiences in a general population sample: a prospective study on the mediating role of emotion regulation. Eur. Psychiatry 42, 111-119.

Longden, E., Sampson, M., Read, J., 2015. Childhood adversity and psychosis: generalised or specific effects? Epidemiol. Psychiatr. Sci. 25, 349-359.

Lysaker, P.H., Nees, M.A., Lancaster, R.S., Davis, L.W., 2004. Vocational function among persons with schizophrenia with and without history of childhood sexual trauma. J. Trauma. Stress 17 (5), 435-438.

MacBeth, A., Gumley, A., Schwannauer, M., Fisher, R., 2011. Attachment states of mind, mentalization, and their correlates in a first-episode psychosis sample. Psychol. Psychother.: Theory, Res. Pract. 84 (1), 42-57.

Maxwell, S.E., Cole, D.A., Mitchell, M.A., 2011. Bias in cross-sectional analyses of longitudinal mediation: partial and complete mediation under an autoregressive model. Multivar. Behav. Res. 46 (5), 816-841.

Mitchley, N.J., Barber, J., Gray, J.M., Brooks, D.N., Livingston, M.G., 1998. Comprehension of irony in schizophrenia. Cogn. Neuropsychiatry 3 (2), 127-138.

Nolte, T., Bolling, D.Z., Hudac, C.M., Fonagy, P., Mayes, L., Pelphrey, K.A., 2013. Brain mechanisms underlying the impact of attachment-related stress on social cognition. Front. Human. Neurosci. 7 (816), 1-12.

O'Driscoll, C., Laing, J., Mason, O., 2014. Cognitive emotion regulation strategies, alexithymia and dissociation in schizophrenia, a review and meta-analysis. Clin. Psychol. Rev. 34 (6), 482-495.

Pollak, S.D., Cicchetti, D., Hornung, K., Reed, A., 2000. Recognizing emotion in faces: developmental effects of child abuse and neglect. Dev. Psychol. 36 (5), 679.

Pears, K., Fisher, P.A., 2005. Developmental, cognitive, and neuropsychological functioning in preschool-aged foster children: associations with prior maltreatment and placement history. J. Dev. Behav. Pediatr. 26 (2), 112-122.

Read, J., van Os, J., Morrison, A.P., Ross, C.A., 2005. Childhood trauma, psychosis and schizophrenia: a literature review with theoretical and clinical implications. Acta Psychiatr. Scand. 112 (5), 330-350.

Read, J., Gumley, A., 2010. Can attachment theory help explain the relationship between childhood adversity and psychosis. Tell. Stories 51-94.

Rogosch, F.A., Cicchetti, D., Aber, J.L., 1995. The role of child maltreatment in early deviations in cognitive and affective processing abilities and later peer relationship problems. Dev. Psychopathol. 7 (4), 591-609.

Schenkel, L.S., Spaulding, W.D., DiLillo, D., Silverstein, S.M., 2005. Histories of childhood maltreatment in schizophrenia: relationships with premorbid functioning, symptomatology, and cognitive deficits. Schizophr. Res. 76 (2), 273-286.

Selten, J.P., van der Ven, E., Rutten, B.P., Cantor-Graae, E., 2013. The social defeat hypothesis of schizophrenia: an update. Schizophr. Bull. 39 (6), 1180-1186.

Selten, J.P., Cantor-Graae, E., 2014. Childhood trauma and the treatment for psychotic disorder. Acta Psychiatr. Scand. 129 (6), 479-480.

Sergi, M.J., Rassovsky, Y., Widmark, C., Reist, C., Erhart, S., Braff, D.L., Marder, S.R., Green, M.F., 2007. Social cognition in schizophrenia: relationships with neurocognition and negative symptoms. Schizophr. Res. 90 (1), 316-324.

Shipman, K.L., Zeman, J., 1999. Emotional understanding: a comparison of physically maltreating and nonmaltreating mother-child dyads. J. Clin. Child Psychol. 28 (3), 407-417.

Spauwen, J., Krabbendam, L., Lieb, R., Wittchen, H.-U., Van Os, J., 2006. Impact of psychological trauma on the development of psychotic symptoms: relationship with psychosis proneness. Br. J. Psychiatry 188 (6), 527-533.

Sprong, M., Schothorst, P., Vos, E., Hox, J., Van Engeland, H., 2007. Theory of mind in schizophrenia. Br. J. Psychiatry 191 (1), 5-13.

Stain, H.J., Brønnick, K., Hegelstad, W.T., Joa, I., Johannessen, J.O., Langeveld, J., Mawn, L., Larsen, T.K., 2013. Impact of interpersonal trauma on the social functioning of adults with first-episode psychosis. Schizophr. Bull. 40, 1491-1498.

Susser, E., Widom, C.S., 2012. Still searching for lost truths about the bitter sorrows of childhood. Schizophr. Bull. 38 (4), 672-675.

Tikka, M., Luutonen, S., Ilonen, T., Tuominen, L., Kotimäki, M., Hankala, J., Salokangas, R.K., 2013. Childhood trauma and premorbid adjustment among individuals at clinical high risk for psychosis and normal control subjects. Early Interv. Psychiatry 7 (1), 51-57.

Trémeau, F., 2006. A review of emotion deficits in schizophrenia. Dialog. Clin. Neurosci. 8 (1), 59-70. 
van Dam, D., van Nierop, M., Viechtbauer, W., Velthorst, E., van Winkel, R., Bruggeman, R., Cahn, W., De Haan, L., Kahn, R., Meijer, C., 2015. Childhood abuse and neglect in relation to the presence and persistence of psychotic and depressive symptomatology. Psychol. Med. 45 (7), 1363-1377.

Van Donkersgoed, R.J., De Jong, S., Van der Gaag, M., Aleman, A., Lysaker, P.H., Wunderink, L., Pijnenborg, G.H.M., 2014. A manual-based individual therapy to improve metacognition in schizophrenia: protocol of a multi-center RCT. BMC Psychiatry 14 (1), 14-27.

van Os, J., Kenis, G., Rutten, B.P.F., 2010. The environment and schizophrenia. Nature 468 (7321), 203-212.

Varese, F., Smeets, F., Drukker, M., Lieverse, R., Lataster, T., Viechtbauer, W., Read, J., van Os, J., Bentall, R.P., 2012. Childhood adversities increase the risk of psychosis: a meta-analysis of patient-control, prospective-and cross-sectional cohort studies. Schizophr. Bull. 38 (4), 661-671.

Walston, F., Blennerhassett, R.C., Charlton, B.G., 2000. "Theory of mind", persecutory delusions and the somatic marker mechanism. Cogn. Neuropsychiatry 5 (3), 161-174.

Wei, M., Shaffer, P.A., Young, S.K., Zakalik, R.A., 2005. Adult attachment, shame, depression, and loneliness: the mediation role of basic psychological needs satisfaction. J. Couns. Psychol. 52 (4), 591.

Weijers, J., ten Kate, C., Eurelings-Bontekoe, E., Viechtbauer, W., Rampaart, R., Bateman, A., Selten, J.-P., 2016. Mentalization-based treatment for psychotic disorder: protocol of a randomized controlled trial. BMC Psychiatry 16 (1), 191. 